\title{
Subcritical ethylic biodiesel production from wet animal fat and vegetable oils: a net energy ratio analysis
}

\author{
Emerson A. Sales ${ }^{\mathrm{a}, \mathrm{d}, *}$, Maria L. Ghirardi ${ }^{\mathrm{b}}$, Orlando Jorquera ${ }^{\mathrm{c}, \mathrm{d}}$ \\ aDepartment of Physical Chemistry, Chemistry Institute, Federal University of Bahia, \\ IQ/UFBA. Campus Universitario de Ondina, Salvador - BA, CEP 40.170-290, Brazil. \\ mailto:eas@ufba.br \\ ${ }^{b}$ National Renewable Energy Laboratory (NREL), 1617 Cole Blvd., Golden, C080401, \\ USA. mailto:maria.ghirardi@nrel.gov \\ ${ }^{c}$ Formation Center in Environmental Science (FCES), Campus Sosigenes Costa, Porto \\ Seguro, Federal University of South of Bahia-UFSB, Rodovia Porto Seguro-Eunapolis, \\ BR-367, km 10, CEP45810-000, Brazil.mailto:ojorquerc@gmail.com \\ 'Laboratory of Bioenergy and Catalysis (LABEC), Polytechnic School of UFBA, Rua \\ Aristides Novis, 2, 2nd floor, Federacao, Salvador - BA, CEP 40.210-630, Brazil.
}

\begin{abstract}
Ethylic transesterification process for biodiesel production without any chemical or biochemical catalysts at different subcritical thermodynamic conditions was performed using wet animal fat, soybean and palm oils as feedstock. The results indicate that $2 \mathrm{~h}$ of reaction at $240^{\circ} \mathrm{C}$ with pressures varying from 20 to 45 bar was sufficient to transform almost all lipid fraction of the samples to biodiesel, depending on the reactor dead volume and proportions between reactants. Conversions of $100 \%, 84 \%$ and $98.5 \%$ were obtained for animal fat, soybean oil and palm oil, respectively, in the presence of water, with a net energy ration values of 2.6, 2.1 and 2.5 respectively. These results indicate that the process is energetically favorable, and thus represents a cleaner technology with environmental advantages when compared to traditional esterification or transesterification processes.
\end{abstract}

Keywords: Biodiesel, FAEEs, subcritical, Animal Fat, Net Energy Ratio.

\footnotetext{
* Corresponding author: Laboratory of Bioenergy and Catalysis (LABEC), Polytechnic School of UFBA, Rua Aristides Novis, 2, 2nd floor, Federacao, Salvador - BA, CEP 40.210630, Brazil. Tel: +56-71-3283.9790

Email address: eas@ufba.br(Emerson A. Sales )
} 


\section{Nomenclature.}

AF: animal fat; FFA: free fatty acids; FAEEs: fatty acid ethyl esters; FAMEs: fatty acid methyl esters; GC: gas chromatography; IS: internal standard; NER: Net Energy Ratio; TG: triglycerides; TGpcar: TG peak corrected after reaction; TGpar: TG peak area after reaction; TGpbr: TG peak area before reaction; ISpbr: IS peak area before reaction; ISpar: IS peak area after reaction; TGtc: TG total conversion; TGpcar: TG peak corrected area after reaction; FAEEsmax: Maximum possible formation of FAEEs peak area; FFApbr: FFA peak area before reaction; $E_{\mathrm{FAEEs}}$ : Energy obtained from FAEEs; $\mathrm{E}_{\mathrm{cpm}}$ : $\quad$ Energy consumption from the power meter; $\mathrm{E}_{\mathrm{rfr}}$ : Energy requirements for the reaction.

\section{Introduction}

The transesterification reaction of vegetable oils to produce fatty acid methyl or ethyl esters (FAMEs or FAEEs) can be catalyzed by acids, bases or enzymes, among other processes [1]. The predominant FAMEs employed in the biodiesel industry in the world are derived from soybean, rapeseed, and palm oils [2]. Currently, most commercial processes employ methanol to perform the transesterification of triglycerides, catalyzed by a strong base

$(\mathrm{KOH})$ in a homogeneous process to produce FAMEs. This is due to the fast transesterification reaction in the presence of alcohol soluble bases and to the low cost of alkaline material, but this process involves many treatment steps previous to and post-reaction, with generation of large amounts of effluents and waste. Besides, the use of a soluble base as a catalyst is not suitable for processing low quality raw materials, such as animal fat and palm oil that usually contain traces of water and high amounts of free fatty acids which readily react via the saponification reaction, generating soaps and hindering the separation of the products, consumes the catalyst and reduces its efficiency[3]. Likozar and Levec [4] performed a very detailed kinetic study of the transesterification reaction of various vegetable oils, using various alcohols, via homogeneous catalysis with $\mathrm{KOH}$. The authors showed that the alcohol influences the mass transfer rate-determining region through its physical properties and the reaction rate-determining region depending on its chemical properties and reactivity. Using methanol, the initial emulsion formed, gradually becoming a pseudo-homogeneous phase with the progress of the transesterification reaction may explain its better performance among all alcohols tested. However, methanol is very toxic in comparison with 
ethanol[5]. The transesterification reaction using ethanol is safer and an environmental friendly alternative. In Bazil, where ethanol is produced at large scale and is more cost $\mathrm{e} \downarrow$ ective, fatty acid ethyl esters (FAEEs) should be produced instead of fatty acid methyl esters (FAMEs). The proposed reaction mechanism for the traditional alkaline transesterification occurs by a nucleophilic attack of the methoxide groups (resulting from the reaction of the alkali with the alcohol) at the triglyceride carbonyl groups. An undesirable saponification reaction occurs between the alkali and triglyceride, generating a fatty acid salt (soap) and glycerol. The use of acid catalysts solves this problem, but the kinetics of the reaction is much slower[1],[6],[7],[8],[9], and presents problems of corrosion of the equipment used in the process. The reaction mechanism for acid catalysis is initiated by an electrophilic attack of the acidic proton, generating protonic intermediate species, followed by a nucleophilic attack of the alcohol to the triglycerides[8]. Currently both the alkaline and acid transesterification processes feature a number of technological and environmental challenges among which are: a) the conditioning of the reactants with acids and strong bases prior to the alkaline transesterification reaction; b) the generation of large volumes of contaminated water resulting from the neutralization of the produced biodiesel; c) the generation of waste in the purification of glycerol's step; d) the lack of modularity of the processes; e) batch operation; f) the generation of soap when using the alkaline catalyst $(\mathrm{KOH})$; g) the high toxicity of methanol; and h) the slowest kinetics of the reaction catalyzed by acidic or some heterogeneous catalysts.

Enzymatic process, on the other hand, has important advantages which include mild reaction conditions and the possibility of using feedstock with high free fatty acid content, but generally presents kinetics limitations. Mangas -Sanchez and Adlercreutz [10] recently proposed the use of silica particles, which permitted a larger surface area in the interphase, overcoming mass transfer limitations and thus increasing the rate of the triacylglycerol and free fatty acids conversion process to biodiesel. The authors used Thermomyces lanuginosus lipase as catalyst in an aqueous/organic two-phase system and a high oleic acid content starting material in order to simulate low-quality oil obtaining a biodiesel yield of $96 \%$, with $2 \%$ monoacylglycerols and $2 \%$ diacylglycerols remaining after $5 \mathrm{~h}$ under the mild conditions used $\left(37^{\circ} \mathrm{C}\right)$, but further increases in the efficiency of the enzymatic process are desired to make it attractive and suitable for large-scale applications.

Transesterification reactions in supercritical and subcritical thermodynamic conditions have been described in the literature, using methanol or 
102 ethanol and avoiding most of the above-mentioned problems [11],[12], or try-

ing to find, by mathematical modeling, the best thermodynamic conditions to produce biodiesel from triglycerides using methanol, subcritical or supercritical [13], [14],[15],[16],[17],[18],[19],[20],[21]. Generally, under subcritical thermodynamic conditions, short reaction times are sufficient to achieve conversion yields above $90 \%$ in the absence of catalysts. Compared to the alkaline and acid reaction mechanisms, the proposed mechanism for the supercritical (and perhaps subcritical) transesterification reaction [22] indicates a direct attack of the alcohol to the triglyceride's carbonyl groups, forming an intermediate diglyceride and then the methyl or ethyl esters of fatty acids. High yields and very low reaction time (about $5 \mathrm{~min}$.) have been achieved, in which the major critical factors are the optimization of the mix between the reactants and the characteristics of the supercritical fluids. Water use in subcritical conditions is a technologically cleaner alternative that has been successfully applied in various processes such as extraction, hydrolysis [23], [24] and wet oxidation of organic compounds, including glycerol [25],[26]. Recently the production of biodiesel by transesterification using methanol and water in subcritical condition was described with conversion rates above $90 \%$ and reaction time of 4 hours [11].The main problem of this process is the huge energy demand. Some authors of the same research group showed that wet activated sludge may be converted directly into biodiesel using only subcritical water as catalyst [24], but the long reaction time (24h) at 175 ${ }^{\circ} \mathrm{C}$ also implies in huge energy demand. More recently, they showed again that subcritical water act as a catalyst for esterification with methanol of fatty acids obtained from low quality feedstock oil [27], at $175-205{ }^{\circ} \mathrm{C}$ and 2.0-2.8 MPa. A catalyst-free two-step process has been proposed, with hydrolysis of triglycerides to fatty acids in subcritical water and subsequent methyl esterification of these acids in supercritical methanol [23]. This process presents some advantages, as glycerol is removed away prior to methyl esterification, avoiding backward reaction; moreover, because the fatty acids act as acid catalysts, smaller amounts of methanol are used. All these aspects may contribute to higher energy efficiency.

A key point for the production of any fuel is that the energy produced per product unit must be greater than the energy expended to obtain this product (which, in the present case, is biodiesel). The metrics used here to evaluate the energetic feasibility of the process is the net energy ratio (NER), which can be defined as "the ratio of the total energy production to the primary non-renewable energy requirements" [28]. 
In Brazil, the main feedstock used for biodiesel is soybean oil, varying between $70 \%$ and $85 \%$ of the total biodiesel matrix each year, but animal fat corresponds to $10 \%$ in average, and reached $25 \%$ in 2008 . Animal fat is abundant in Brazil, as this country is the second meat producer in the world, but many biodiesel industries limit the addition of animal fat to 30 wt.\% of the total feedstock, generally combined with the soybean oil, due to its high acidity and high viscosity, which may cause clogging of pipes and equipment. To achieve this ratio of $30 \mathrm{wt} . \%$ in the mixture, a pretreatment is required to remove the free fatty acids from the animal fat. This treatment is made through a reaction with sodium hydroxide, followed by centrifugation and neutralization with hydrochloric acid, and all these steps generate more fatty acid residues. The process presented here has no such limitations, as it can use raw animal fat as feedstock, with no need for mixtures, and generates almost no effluents and residues, compared to the all traditional processes. This process has other intrinsic advantages due to the absence of catalysts, as homogeneous alkaline catalysts causes the undesirable saponification reaction, and the homogeneous acid catalysts may cause corrosion problems, and both led to the intrinsic generation of effluents. Moreover, solid catalysts implies on mass transfer limitations between phases and within the pores of the catalyst itself, resulting in lower conversion of the feedstock. Enzymatic catalysts also have limitations; mass transfer of substrate and products between the phases constitutes a bottleneck to overcome in these bioprocesses.

In this study we report a biodiesel production technique using subcritical thermodynamic conditions for ethylic transesterification reaction of wet animal fats and vegetable oils with high content of free fatty acids, investigating the reaction conditions that enable a NER grater than one. Since no catalyst is employed, the process presented here is simpler and environmental friendly than traditional methods, mainly due to the very low generation of effluents and residues.

\section{Materials and Methods}

\subsection{Chemicals.}

Animal fat (35 wt.\% free fatty acids and 0.3 wt.\% water) was supplied by FOSFOCAL, a company located at Itapetinga, Bahia, Brazil. Refined edible soybean oil ( $0.3 \mathrm{wt} . \%$ free fatty acids and $0.1 \mathrm{wt} . \%$ water) and palm oil (5 wt.\% free fatty acids and 0.1 wt. $\%$ water) were obtained from a commercial source (local supermarket, Salvador, Bahia, Brazil). The detailed 
composition of all feedstock is shown in Table 1. The standard mixture of fatty acid ethyl esters (FAEEs) (49454-U, C4-C24 Even Carbon Saturated FAEEs) was purchased from Supelco (Bellefonte, PA, USA). A standard triglyceride, namely glyceryl trioleate was purchased from Sigma-Aldrich. The standard mix of Mono, Di and Triglyceride (code 1787) was purchased from Supelco (Bellefonte, PA, USA). All other chemicals such as ethanol, hexane and methyl heptadecanoate were analytical grade reagent obtained from Sigma-Aldrich.

\section{Table 1}

\subsection{Equipment for biodiesel production.}

Biodiesel from animal fat and vegetable oils was obtained by a one-step subcritical process without catalyst addition, using water and ethanol according to the proportion indicated in the design of experiments described in the next section, using a $100 \mathrm{~mL}$ Parr reactor (Parr Instrument Company, Moline, Illinois) mounted as described in the Fig. 1. The total volume used for each experiment was $60 \mathrm{~mL}$. The reactor was monitored and controlled (PID controller) through a program designed by the authors, using the LabView software (National Instruments). The reactor was operated in batch; the reagents (ethanol, triglycerides and water) were added and heated under mixing (stirring speed $1200 \mathrm{RPM}$ ) until the mixture reached the set point temperature, with a mean heating rate of $13.3{ }^{\circ} \mathrm{C} / \mathrm{min}$. The time to reach the highest temperature used in the experiments $\left(240{ }^{\circ} \mathrm{C}\right)$ was around 40 min. No inert gas or co-solvent were used. The reaction time and the set point were pre-set for each experiment. The main controlled variable was the internal temperature, with variation lower than $1{ }^{\circ} \mathrm{C}$, so the pressure varied with the ratio of reactants, from 20 to 45 bar. For comparison reasons, it was assumed that the reaction started when the desired temperature was reached. At the end of the reaction, the reactor was cooled to room temperature and the mixture was removed for subsequent chromatographic analysis.

Fig. 1

\subsection{Experimental design.}

A statistical two levels half factorial design with center point [29] was 
used. The independent parameters considered were: temperature, reaction time, water/fat or water/triglycerides molar ratio and ethanol/fat or ethanol/triglycerides molar ratio. The rate of conversion of free fatty acids and triglycerides to biodiesel was chosen as the main response variable, calculated as shown below. Additionally, the FAEEs's yield was estimated, and the NER for each experiment was calculated as also shown below. The statistical analysis of the results was done using the software Minitab version 17.

\subsection{GC analysis.}

Qualitative and quantitative analysis of FAEEs, monoglycerides, diglycerides and triglycerides were performed using a Bruker Scion 456-GC equipped with a split/splitless injector and a flame ionization detector (FID). Separation was carried out using a BR-biodiesel (5\% phenyl $95 \%$ methyl polysiloxane stationary phase modified for high temperature) capillary column $(10 \mathrm{~m}$ $\mathrm{x} 0.32 \mathrm{~mm}$ internal diameter, $0.1 \mathrm{~m}$ film thickness) supplied by Bruker. The operation conditions were: split/splitless ratio 100:1, injector temperature $280^{\circ} \mathrm{C}$, detector temperature $380^{\circ} \mathrm{C}$, column temperature profile: $80^{\circ} \mathrm{C}$ for $1 \mathrm{~min}$., ramp to $300^{\circ} \mathrm{C}$ at $7^{\circ} \mathrm{C} / \mathrm{min}$., ramp to $370^{\circ} \mathrm{C}$ at $30^{\circ} \mathrm{C} / \mathrm{min}$., plus 10 min. at $370^{\circ} \mathrm{C}$. The total runtime was $45 \mathrm{~min}$., and the injection sample volume was $1 \mathrm{~L}$. Helium was used as the carrier gas with a linear velocity of $55 \mathrm{~cm} / \mathrm{s}$ at $80^{\circ} \mathrm{C}$. The peak assignments were made by comparison with standards samples of fatty acid ethyl esters (FAEEs) and mono, di and triglyceride (monoolein, diolein and triolein) (Fig. 2).

Fig. 2

\subsection{Sample preparation.}

The biodiesel sample obtained after the reaction was weighed (100 mg approximately) and dissolved in $1 \mathrm{~mL}$ of hexane. Prior to the injection in the chromatograph, a known amount of internal standard $(1 \mathrm{mg} / \mathrm{mL}$ of methyl heptadecanoate) was added to the vial. The results presented in this study represent the mean value of three injections of each sample obtained from the experiments. 


\subsection{Total conversion calculation.}

The peak areas of animal fat or vegetable oils triglycerides (TG) and free fatty acids (FFA) before and after reaction were determined as well as the areas of the internal standard (methyl heptadecanoate) peak for each injection. The total conversion of triglycerides was determined using the

TG peak areas after the reaction corrected with respect to the areas of the internal standard peak (IS) as follows:

$$
T \text { Gpcar }=T \text { Gpar }(I S p b r) /(I S p a r)(1)
$$

Thus, the total conversion of triglycerides to biodiesel was calculated as:

$$
\text { TGtc } \%=((T G p b r-T \text { Gpcar }) / \text { TGpbr })) \times 100
$$

The conversion of free fatty acids (present significantly only in the animal fat samples) was calculated using a similar procedure.

\subsection{FAEEs yield estimation.}

Using the total conversion percentage of TG and observing that the fatty acids are easily esterified because their corresponding peaks disappear, the FAEEs yield for each experiment was estimated as follows, considering a similar molar response factor of the detector for molecules with equal number of carbon atoms:

$$
\text { FAEEsmax }=3 \times T G p b r+F F A p b r(3)
$$

. Thus, the estimated yield in FAEEs was calculated as:

FAEEs yield $=(1-($ FAEEsmax $-(($ TGtc $100 \times 3 \times$ TGpbr $)+F F A p b r) /$ FAEEsmax))X100. (4)

\subsection{Net energy ratio (NER) determination.}

The NER measures how much energy is produced per unit of energy spent, and for the production of biodiesel it is calculated as: 


\section{$N E R=$ Energy content in biodiesel/all energy requirements (5)}

To determinate the energy requirements for the transesterification process using the Parr reactor used here (Fig. 1), a volume of $60 \mathrm{~mL}$ of distilled water was placed inside the reactor, which was brought to the maximum operating temperature $\left(240^{\circ} \mathrm{C}\right)$. The energy consumption in W.h was measured through a power meter (Kron model Mke-01). This amount of energy comprises the energy requirement for heating all parts of the equipment, heating the fluid to the desired temperature, for the stirring, and energy losses. Water was used for reference because it is a simple fluid, with great availability of thermodynamic data. The theoretical amount of energy necessary to bring the liquid water at $30^{\circ} \mathrm{C}$ to superheated water at $240^{\circ} \mathrm{C}$ was calculated using the latent and sensible heat data, yielding $188 \mathrm{~kJ}$ or $55.3 \mathrm{~W} . \mathrm{h}$. The comparison between the measured value and the theoretical one indicated a loss of heat of $83 \%$ in the reaction system, due to bad insulation of the whole apparatus. Obviously, this energy loss must be minimized in the development of a future industrial process. This loss must be deducted in order to determine the net energy requirement for the reaction itself. The energy consumption for each reaction was thus measured each time and corrected for this heat loss to determine the net energy requirement for the reaction itself and then the NER was calculated, taking in account the energy corresponding to the biodiesel produced. The biodiesel energy content (ethyl ester) was considered to be $40.97 \mathrm{~kJ} / \mathrm{g}$ [30]. Thus, the NER was calculate as:

$$
\begin{gathered}
E_{c p m}=W . h \times 3.6(\mathrm{~kJ})(6) \\
E_{r f r}=E_{c p m} \times 0.17(1-0.83)(7) \\
E_{F A E E s}=\text { Feedstock }(\mathrm{g}) \times \text { TGtc } \times \text { FAEEs yield } \times 40.97(\mathrm{~kJ} / \mathrm{g})
\end{gathered}
$$

$$
N E R=E_{F A E E s} / E_{r f r}(9)
$$




\section{Results and Discussion}

The experimental statistical and the main results of total conversion, NER, and yield of FAEEs obtained from the nine experiments conducted for the transesterification of animal fat are showed in Table 2. The best operating condition was found at a temperature of $240^{\circ} \mathrm{C}$ and reaction time

$120 \mathrm{~min}$., using molar ratio water/fat $=5$ and molar ratio ethanol/fat $=10$, for which a full conversion of the feedstock was obtained, with almost no diglycerides and very low monoglycerides at the end of reaction, giving $98 \%$ of FAEEs's yield, and positive NER value (2.6).

\section{Table 2}

As the temperature was the main variable, a precise PID controller as described in the section materials and methods was used to control it, and the pressure varied freely, ranging from 20 to 45 bars among all experiments. At the lower level of temperature, $120^{\circ} \mathrm{C}$, no conversion is observed in these experiments without using catalysts. Indeed, a statistical analysis of the results showed that the temperature is the most important parameter, with significant e $\downarrow$ ect on the three responses, as shown in the Pareto's charts of the standardized main e $\downarrow$ ects for $95 \%$ of confidence (Supplementary file). None of the interactions between two parameters showed statistical significance, for the set of nine experiments considered for analysis.

Fig. 3 exhibits two chromatograms: a) Animal fat feedstock (AF), b) FAEEs produced by the transesterification reactions of this feedstock with ethanol at the operating condition cited above.

Fig. 3

The esterification reaction of the free fatty acids present in the animal fat was complete, as well as the transesterification reaction of the triglycerides with ethanol, as seen in the Fig. 3. An overall conversion of $100 \%$ is observed for this experiment. The standards peaks for monoglyceride (monoolein), diglyceride (diolein), and triglyceride (triolein) allowed us to conclude that: (a) all triglycerides present in the animal fat were converted; (b) no diglycerides remain at the end of reaction; and (c) only a small proportion (about

$2 \%$ ) of the product remains as monoglycerides. The thermodynamic condi- 
tions employed probably allowed a very good mixture between the reactants, which is a key factor in the esterification or transesterification reactions, as non-soluble compounds are involved. The presence of water, despite possible solubility problems in this complex system, was beneficial, as observed in the experiments. This positive effect of water can be seen comparing some results presented in Tab. 2. For example, runs 2 and 3 were conducted at the same temperature $\left(240^{\circ} \mathrm{C}\right)$, same molar ratio ethanol/fat (6), and, despite of the very low time of reaction (30 min.) the total conversion and FAEEs yield results found in run 2, using a molar ratio water/fat 10 times higher, were slightly higher than those of run 3 , showing clearly the beneficial e $\downarrow$ ect of the water in the reaction mechanism. One possibility is that water causes hydrolysis of part the triglycerides forming glycerol and fatty acids; these fatty acids, together with the free fatty acids present in the feedstock (very high content for the animal fat sample used in this work: $35 \mathrm{wt} . \%$ ) react via the esterification reaction with ethanol to form the FAEEs (biodiesel), and more water. This additional amount of water produced in the esterification reaction may cause hydrolysis of the remaining triglycerides, in a cyclic behavior, favoring the overall conversion process. The catalytic effect of subcritical water was explained by Go and co-workers [27] due to the better dissociation of the water molecule into hydroxonium and hydroxide ions, as the $\mathrm{pH}$ of water decreases from 7.4 at $0{ }^{\circ} \mathrm{C}$ to 5.5 at $250{ }^{\circ} \mathrm{C}$, increasing the amount of $\mathrm{H}_{3} \mathrm{O}^{+}$formed.

The esterification reaction is known to be much easier and faster than the transesterification reaction, which normally requires strong acidic or basic catalysts to activate and broke the carbon-oxygen bonds of the triglycerides. The presence of a very high amount of free fatty acids in this feedstock (35 wt.\%) may explain the total conversion observed, as these acids are easily transformed to FAEEs under the thermodynamic conditions employed here. There is also a possibility of catalytic action of the fatty acid itself, as observed by Minami and Saka [23], as they concluded that FA has an important role as acid catalyst in hydrolysis reaction of oils/fats in subcritical water. Moreover, these conditions may also facilitate the nucleophilic attack of the alcohol (ethoxy group) to the carbonyl group of part the triglycerides, forming an intermediate, and subsequently, diglycerides, monoglycerides and finally FAEEs. This transesterification reaction mechanism was suggested by Sawangkeaw and co-workers [22], but under supercritical conditions. Experiments with soybean oil and palm oil were also conducted under analog conditions: temperature $240^{\circ} \mathrm{C}$, reaction time $120 \mathrm{~min}$., molar ratio water/TG 
$=5$ and molar ratio ethanol/TG $=10$. Fig. 4 shows the results of the transesterification reaction using soybean oil as feedstock. This figure presents the chromatograms obtained for the control sample (soybean oil) and the products (FAEEs). In contrast with animal fat, soybean oil has almost only triglycerides, and very low amount of free fatty acids $(0.3 \mathrm{wt} . \%)$. This led to the false conclusion that almost no esterification reaction had occurred, but the presence of water (molar ratio water/triglycerides $=5$ ) suggests that the same two possible transesterification reaction mechanisms cited above did indeed take place: via hydrolysis of part of the triglycerides, or via the nucleophilic attack of the alcohol (ethoxy group) to the carbonyl group of the triglycerides. The reaction via hydrolysis produces glycerol and fatty acids; these acids, together with the free fatty acids present in the feedstock (very low content in this case) react via the esterification reaction with ethanol to form part of the FAEEs observed. As discussed in the case with animal fat, we believe that the transesterification reaction mechanism via the nucleophilic attack of the alcohol to the carbonyl groups of the triglycerides is also possible under the conditions employed here, as extra experiments conducted with very low amount of water (no extra addition of water and no catalysts at all) also allowed the reaction to occur, although at a lower rate, when compared to the abovementioned conditions. As seen in Fig. 4, not all triglycerides present in the feedstock were converted, and the calculated conversion was $84 \%$. Moreover, some diglycerides (very few) remain at the end of reaction, and a significant proportion (about $16 \%$ ) of the product remains as monoglycerides.

Fig. 4

Fig. $\quad 5$ shows the results for the production of FAEEs using palm oil as feedstock, performed at the same experimental conditions. Similarly to the case using soybean oil, not all triglycerides present in the feedstock were converted, but the calculated total conversion was $98.5 \%$ for this run. Analogously, some diglycerides (very few) remain at the end of reaction, and a significant proportion (about $10 \%$ ) of the product persists as monoglyceride. It is important to stress, however, that the total triglyceride conversion was significantly higher, under the same reaction conditions. This result confirms the assumption made for the case of animal fat, i.e., that the presence of free fatty acids in much higher amount in palm oil (5 wt.\% against $0.3 \mathrm{wt} . \%$ for soybean oil) results in the formation of FAEEs by direct esterification, a 
much easier and faster reaction than the transesterification, consistent with 410 the higher total conversion observed, in comparison to the soybean feedstock. 411 This fact reinforce the possibility of catalytic action of the fatty acids in the hydrolysis reaction of oils/fats in subcritical water, as mentioned before.

Finally, it may be stressed that the FAEEs produced in all experiments 414 with the three feedstock ranged from 14 carbon atoms up to 22 carbon atoms, by comparison with the standards (Fig. 2), and the major part of them stayed at around 18 carbon atoms, as expected.

Fig. 5

The energy consumption, as well as the net energy ratio (NER), was determined in each one of the experiments performed. Table 3 presents the

NER for animal fat biodiesel, vegetable oils biodiesel and other sources for bioenergy production, for comparison [31],[32],[33]].

Table 3

To achieve a positive energy balance, the energy content of the biodiesel produced must be greater than the total energy used to obtain it, meaning NER values greater than one. Many experiments performed in this study met this criterion, and the three cases presented in Tab. 3 were among the best ones, which qualifies this process as high potential for industrial application. Some operational conditions exhibited greater NER values, but with low conversion of feedstock, and higher by-products generation. Based on the results presented, we can conclude that crude, or used vegetable oils or animal fats may be used to produce biodiesel by this procedure, since the presence of free fatty acids accelerates the overall reaction rate, increasing the total conversion efficiency. Nevertheless, this process can operate with a broad range of water content in the feedstock, as high water content also showed a positive effect. The water/triglycerides molar ratio has an important role in the process. The presence of water at low ratios (less than 1.0) allowed the reaction to occur with very high values of NER (greater than 6.0), and excellent conversions (greater than $98 \%$ ), but the product exhibited high contents of mono and diglycerides. As the international specifications for biodiesel require very low content of both mono and diglycerides, the parameter water/triglycerides ratio must be optimized in a future work, aiming 446 at a positive NER and final product specification meeting the standards, at 
higher rates of production, to allow scale-up of the process.

\section{Conclusions}

The presence of water and free fatty acids improved the conversion in the hydrolysis, esterification and transesterification reactions of animal fat, soybean and palm oils in the presence of subcritical ethanol. The energy content in the biodiesel produced was greater than the net energy requirements to the process (NER greater than one), at $240{ }^{\circ} \mathrm{C}, 2 \mathrm{~h}$ of reaction, with pressures varying from 20 to 45 bar. These results indicate that the process is energetically favorable, and thus represents a cleaner technology with great environmental advantages when compared to traditional esterification or transesterification processes. The energetic feasibility using the net energy ratio (NER) should be considered to any process suitable for large-scale applications.

\section{Acknowledgements}

This work was supported by the National Council for Scientific and Technological Development of Brazil (CNPq), [grant 420592,2013]. M. L. Ghirardi was supported by NRELs Fellow Program.

\section{References}

[1] A. Demirbas, Comparison of transesterification methods for production of biodiesel from vegetable oils and fats, Energy Conversion and Management 49 (1) (2008) 125-130.

[2] D. Bajpai, V. Tyagi, Biodiesel: source, production, composition, properties and its benefits, Journal of Oleo Science 55 (10) (2006) 487-502.

[3] J. Machek, Kinetics and mechanism of the koh-catalyzed methanolysis of rapeseed oil for biodiesel production, Eur. J. Lipid Sci. Technol 104 (2002) 728-737.

[4] B. Likozar, J. Levec, Transesterification of canola, palm, peanut, soybean and sunflower oil with methanol, ethanol, isopropanol, butanol and tert-butanol to biodiesel: modelling of chemical equilibrium, reaction kinetics and mass transfer based on fatty acid composition, Applied Energy 123 (2014) 108-120. 
[5] M. Pohanka, et al., Toxicology and the biological role of methanol and ethanol: Current view, Biomed Pap Med Fac Univ Palacky Olomouc Czech Repub.

[6] A. S. Ramadhas, S. Jayaraj, C. Muraleedharan, Biodiesel production from high $\downarrow$ a rubber seed oil, Fuel 84 (4) (2005) 335-340.

[7] R. Tesser, M. Di Serio, M. Guida, M. Nastasi, E. Santacesaria, Kinetics of oleic acid esterification with methanol in the presence of triglycerides, Industrial \& engineering chemistry research 44 (21) (2005) 7978-7982.

[8] E. Lotero, Y. Liu, D. E. Lopez, K. Suwannakarn, D. A. Bruce, J. G. Goodwin, Synthesis of biodiesel via acid catalysis, Industrial \& engineering chemistry research 44 (14) (2005) 5353-5363.

[9] J. Marchetti, A. Errazu, Esterification of free fatty acids using sulfuric acid as catalyst in the presence of triglycerides, Biomass and Bioenergy 32 (9) (2008) 892-895.

[10] J. Mangas-Sánchez, P. Adlercreutz, Highly efficient enzymatic biodiesel production promoted by particle-induced emulsification, Biotechnology for biofuels 8 (1) (2015) 1.

[11] Y.-H. Ju, L. H. Huynh, Y. A. Tsigie, Q.-P. Ho, Synthesis of biodiesel in subcritical water and methanol, Fuel 105 (2013) 266-271.

[12] E. Markočič, B. Kramberger, J. G. van Bennekom, H. J. Heeres, J. Vos, Ž. Knez, Glycerol reforming in supercritical water; a short review, Renewable and Sustainable Energy Reviews 23 (2013) 40-48.

[13] V. Anikeev, D. Stepanov, A. Yermakova, Thermodynamics of phase and chemical equilibrium in the processes of biodiesel fuel synthesis in subcritical and supercritical methanol, Industrial \& Engineering Chemistry Research 51 (13) (2012) 4783-4796.

[14] S. Glišić, I. Lukic, D. Skala, Biodiesel synthesis at high pressure and temperature: analysis of energy consumption on industrial scale, Bioresource technology 100 (24) (2009) 6347-6354.

[15] S. B. Glisic, A. M. Orlovic, Modelling of non-catalytic biodiesel synthesis under sub and supercritical conditions: The influence of phase distribution, The Journal of Supercritical Fluids 65 (2012) 61-70. 
[16] S. Saka, D. Kusdiana, Biodiesel fuel from rapeseed oil as prepared in supercritical methanol, Fuel 80 (2) (2001) 225-231.

[17] F. Nascimento, A. Oliveira, M. Paredes, A. Costa, F. Pessoa, Biodiesel production from supercritical ethanolysis of soybean oil, Chem Eng Trans 32 (2013) 829-834.

[18] S. D'ippolito, J. Yori, M. Iturria, C. Pieck, C. Vera, Analysis of a twostep, noncatalytic, supercritical biodiesel production process with heat recovery, Energy \& Fuels 21 (1) (2007) 339-346.

[19] A. Demirbaş, Biodiesel from vegetable oils via transesterification in supercritical methanol, Energy conversion and management 43 (17) (2002) 2349-2356.

[20] A. Demirbaş, Biodiesel fuels from vegetable oils via catalytic and noncatalytic supercritical alcohol transesterifications and other methods: a survey, Energy conversion and Management 44 (13) (2003) 2093-2109.

[21] A. Demirbas, Production of biodiesel fuels from linseed oil using methanol and ethanol in non-catalytic scf conditions, Biomass and bioenergy 33 (1) (2009) 113-118.

[22] R. Sawangkeaw, K. Bunyakiat, S. Ngamprasertsith, Continuous production of biodiesel with supercritical methanol: optimization of a scaleup plug flow reactor by response surface methodology, Fuel Processing Technology 92 (12) (2011) 2285-2292.

[23] E. Minami, S. Saka, Kinetics of hydrolysis and methyl esterification for biodiesel production in two-step supercritical methanol process, Fuel 85 (17) (2006) 2479-2483.

[24] L. H. Huynh, P. L. T. Nguyen, Q. P. Ho, Y.-H. Ju, Catalyst-free fatty acid methyl ester production from wet activated sludge under subcritical water and methanol condition, Bioresource technology 123 (2012) 112116.

[25] B. Tapah, R. Santos, G. Leeke, Processing of glycerol under sub and supercritical water conditions, Renewable Energy 62 (2014) 353-361. 
[26] I. N. Ahmed, S. Sutanto, L. H. Huynh, S. Ismadji, Y.-H. Ju, Subcritical water and dilute acid pretreatments for bioethanol production from melaleuca leucadendron shedding bark, Biochemical Engineering Journal 78 (2013) 44-52.

[27] A. W. Go, P. L. T. Nguyen, L. H. Huynh, Y.-T. Liu, S. Sutanto, Y.$\mathrm{H}$. Ju, Catalyst free esterification of fatty acids with methanol under subcritical condition, Energy 70 (2014) 393-400.

[28] O. Jorquera, A. Kiperstok, E. A. Sales, M. Embiruçu, M. L. Ghirardi, Comparative energy life-cycle analyses of microalgal biomass production in open ponds and photobioreactors, Bioresource technology 101 (4) (2010) 1406-1413.

[29] R. Mead, The design of experiments: statistical principles for practical applications, Cambridge University Press, 1990.

[30] X. Lang, A. K. Dalai, N. N. Bakhshi, M. J. Reaney, P. Hertz, Preparation and characterization of bio-diesels from various bio-oils, Bioresource technology 80 (1) (2001) 53-62.

[31] J. Hill, E. Nelson, D. Tilman, S. Polasky, D. Ti $\downarrow$ any, Environmental, economic, and energetic costs and benefits of biodiesel and ethanol biofuels, Proceedings of the National Academy of Sciences 103 (30) (2006) 11206-11210.

[32] H. J. Cho, J.-K. Kim, F. Ahmed, Y.-K. Yeo, Life-cycle greenhouse gas emissions and energy balances of a biodiesel production from palm fatty acid distillate (pfad), Applied Energy 111 (2013) 479-488.

[33] J. C. Quinn, T. G. Smith, C. M. Downes, C. Quinn, Microalgae to biofuels lifecycle assessment - multiple pathway evaluation, Algal Research 4 (2014) 116-122. 
Tables

Table 1: Composition in percentage of Fatty Acids contained in the feedstock studied (animal fat, soybean oil and palm oil)

\begin{tabular}{|c|c|c|c|c|}
\hline Fatty Acid Name & Formula & $\begin{array}{c}\% \text { Fatty Acid } \\
\text { in the animal } \\
\text { fat * }\end{array}$ & $\begin{array}{c}\% \text { Fatty Acid } \\
\text { in the } \\
\text { soybean } \\
\text { oil }^{* *}\end{array}$ & $\begin{array}{l}\% \text { Fatty } \\
\text { Acid in the } \\
\text { palm oil** }\end{array}$ \\
\hline Caproic acid & C6:0 & 0.69 & & \\
\hline Caprylic acid & C8:0 & 1.80 & & \\
\hline Capric acid & C10:0 & & & \\
\hline Onedecanoic acid & C11:0 & 0.52 & & \\
\hline Lauric acid & C12:0 & 0.2 & & 0.2 \\
\hline Miristic acid & C14:0 & 2.41 & 0.1 & 1.1 \\
\hline Miristoleic acid & C14:1 & 0.63 & & \\
\hline Palmitic acid & C16:0 & 30.3 & 11 & 44.1 \\
\hline Palmitoleic acid & C16:1 & 1.52 & 0.1 & 0.2 \\
\hline Heptadecanoic acid & C17:0 & 1.13 & & \\
\hline $\begin{array}{l}\text { Cis-10-heptadecanoic } \\
\text { acid }\end{array}$ & C17:1 & 0.33 & & \\
\hline Estearic acid & C18:0 & 23.12 & 4 & 4.4 \\
\hline Oleic acid & C18:1n9c & 24.05 & 23.4 & 39.0 \\
\hline Linoleic acid & $\mathrm{C} 18: 2 \mathrm{n} 6 \mathrm{c}$ & 0.24 & 53.2 & 10.5 \\
\hline Linolenic acid & C18:3n3 & 0.06 & 7.8 & 0.3 \\
\hline Araquidic acid & $\mathrm{C} 20: 0$ & 0.15 & 0.3 & 0.2 \\
\hline Gadolinic acid & C20:1 & 0.7 & & \\
\hline Eicosapentaenoic acid & $\mathrm{C} 20: 5$ & & & \\
\hline Behenic acid & $\mathrm{C} 22: 0$ & 4.6 & 0.1 & \\
\hline Euricic acid & C22:1n9 & 2.4 & & \\
\hline
\end{tabular}




\begin{tabular}{|l|c|c|l|l|}
\hline Tricosanoic acid & C23:0 & 0.9 & & \\
\hline Lignoceric acid & C24 & 0.44 & & \\
\hline
\end{tabular}

*Greentech Laboratory, Escola de Química / Universidade Federal Rio de Janeiro

${ }^{* *}$ http://web.cals.uidaho.edu/biodiesel/tools-for-producers/triglyceride-

molecular-weight-calculator/

Table 2: Experimental design and results of Total Conversion, NER, and yield of FAEEs for the esterification/transesterification of animal fat.

\begin{tabular}{|c|c|c|c|c|c|c|c|}
\hline $\begin{array}{c}\text { Run } \\
\text { Orde } \\
\mathrm{r} \\
\#\end{array}$ & $\begin{array}{c}\text { Tem } \\
\mathrm{p}\end{array}$ & $\begin{array}{c}\left.{ }^{\circ} \mathrm{C}\right) \\
(\mathrm{min})\end{array}$ & $\begin{array}{c}\text { Molar ratio } \\
\text { water/ } \\
\text { triglyceride } \\
\mathrm{s}\end{array}$ & $\begin{array}{c}\text { Molar ratio } \\
\text { ethanol/ } \\
\text { triglyceride } \\
\mathrm{s}\end{array}$ & $\begin{array}{c}\text { Total } \\
\text { Conversio } \\
\mathrm{n} \%\end{array}$ & \begin{tabular}{c} 
NER \\
\hline 1
\end{tabular} & $\begin{array}{c}\text { FAEE } \\
\text { s yield } \\
\%\end{array}$ \\
\hline 2 & 240 & 30 & 5.0 & 6 & 0.0 & 0.0 & 0.0 \\
\hline 3 & 240 & 120 & 0.5 & 6 & 93.1 & 6.1 & 94.3 \\
\hline 4 & 180 & 75 & 2.8 & 8 & 19.7 & 1.2 & 74.2 \\
\hline 5 & 240 & 120 & 5.0 & 10 & 100.0 & 2.6 & 98.0 \\
\hline 6 & 120 & 120 & 0.5 & 10 & 0.0 & 0.0 & 0.0 \\
\hline 7 & 240 & 30 & 0.5 & 10 & 93.6 & 6.2 & 94.3 \\
\hline 8 & 120 & 30 & 5.0 & 10 & 0.0 & 0.0 & 0.0 \\
\hline 9 & 120 & 120 & 5,0 & 6 & 0.0 & 0.0 & 0.0 \\
\hline
\end{tabular}


Table 3: NER for animal fat biodiesel, vegetable oils biodiesel and other sources for bioenergy production.

\begin{tabular}{|l|c|c|}
\hline \multicolumn{1}{|c|}{ Biofuel } & NER & References $^{\mid}$ \\
\hline Animal Fat biodiesel & 2.6 & Authors $^{*}$ \\
\hline Soybean oil biodiesel & 2.1 & Authors $^{*}$ \\
\hline Palm oil biodiesel & 2.5 & Authors $^{*}$ \\
\hline Corn grain ethanol & 1.25 & {$[31]$} \\
\hline Soybean biodiesel & 3.67 & {$[31]$} \\
\hline $\begin{array}{l}\text { Biodiesel from Palm Fatty Acid } \\
\text { Distillate }\end{array}$ & 3.23 & {$[32]$} \\
\hline Biofuels from microalgae & 1,54 & {$[33]$} \\
\hline
\end{tabular}

*Temperature $240{ }^{\circ} \mathrm{C}$, reaction time $120 \mathrm{~min}$., molar ratio water/fat or TG $=5$ and molar ratio ethanol/fat or TG $=10$. 


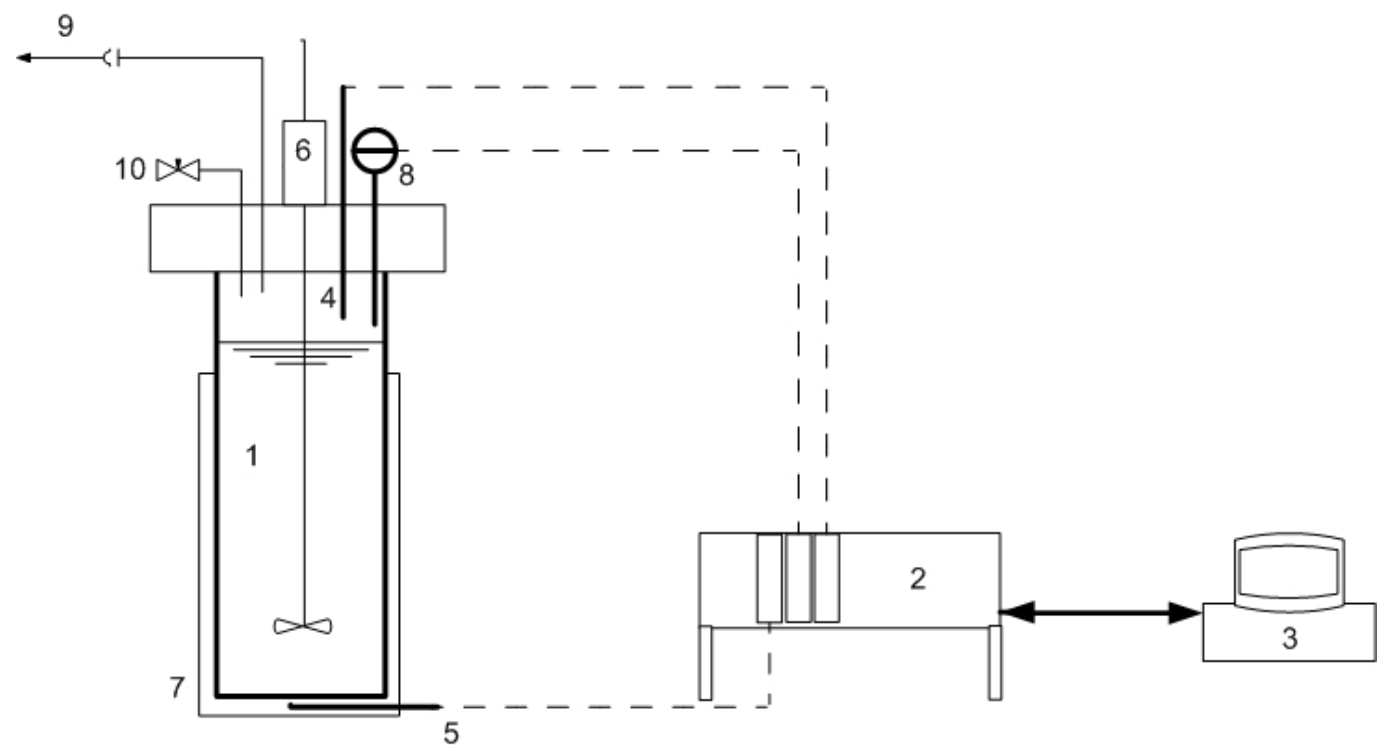

Fig. 1.

Scheme for the experimental setup used for biodiesel production from animal fat under subcritical wet conditions. 1, Parr reactor; 2, DAQ (data acquisition system); 3, computer and graphical interface (LabView); 4, temperature sensor in the reactor; 5, temperature sensor in the heat blanket; 6, magnetic stirrer; 7, heat blanket; 8, pressure sensor and transducer; 9 rupture disc; 10 sampling valve. 


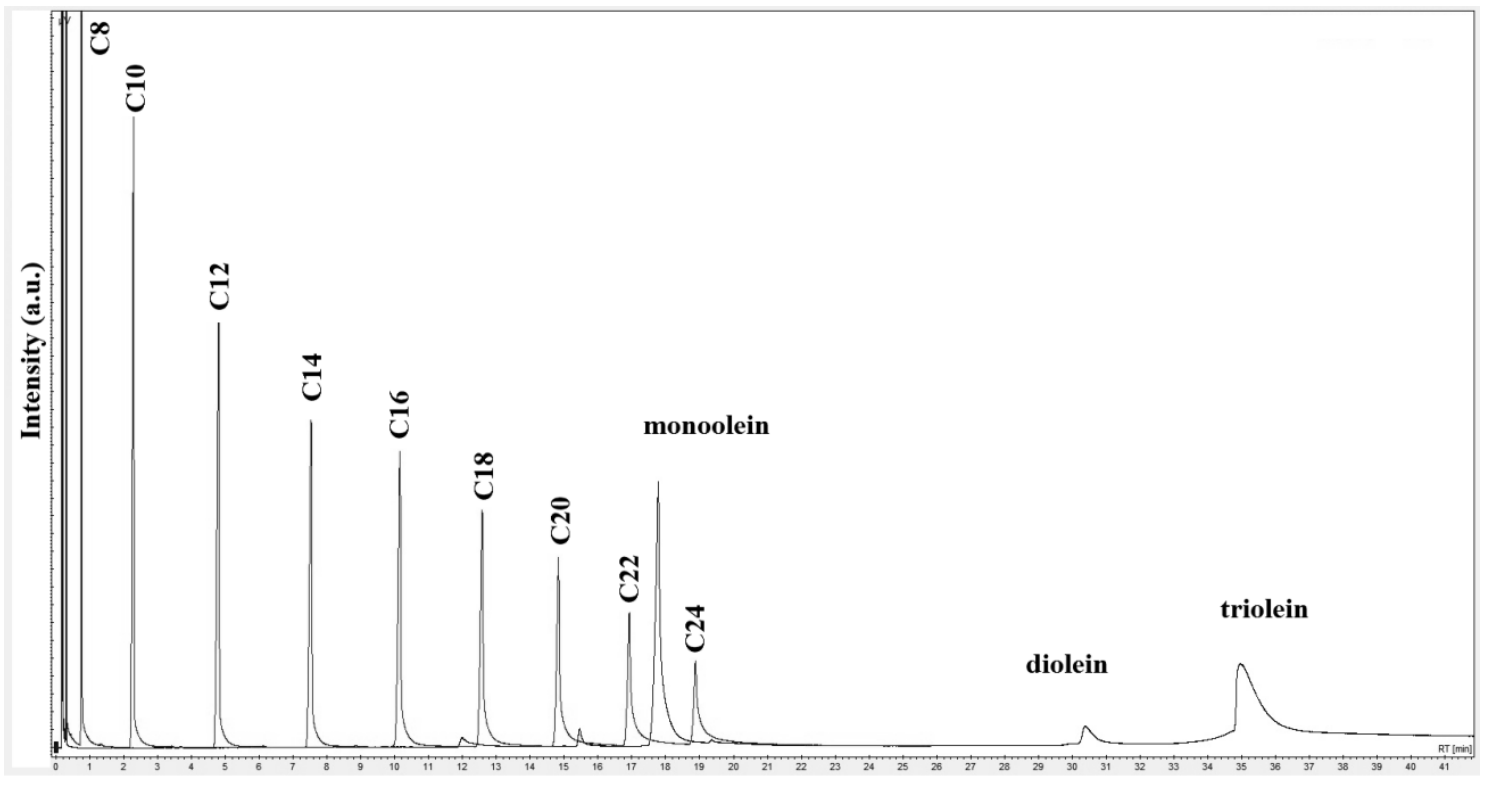

Fig. 2.

Chromatograms of the standards FAEEs, monoglyceride (monoolein), diglyceride (diolein) and triglyceride (triolein). 


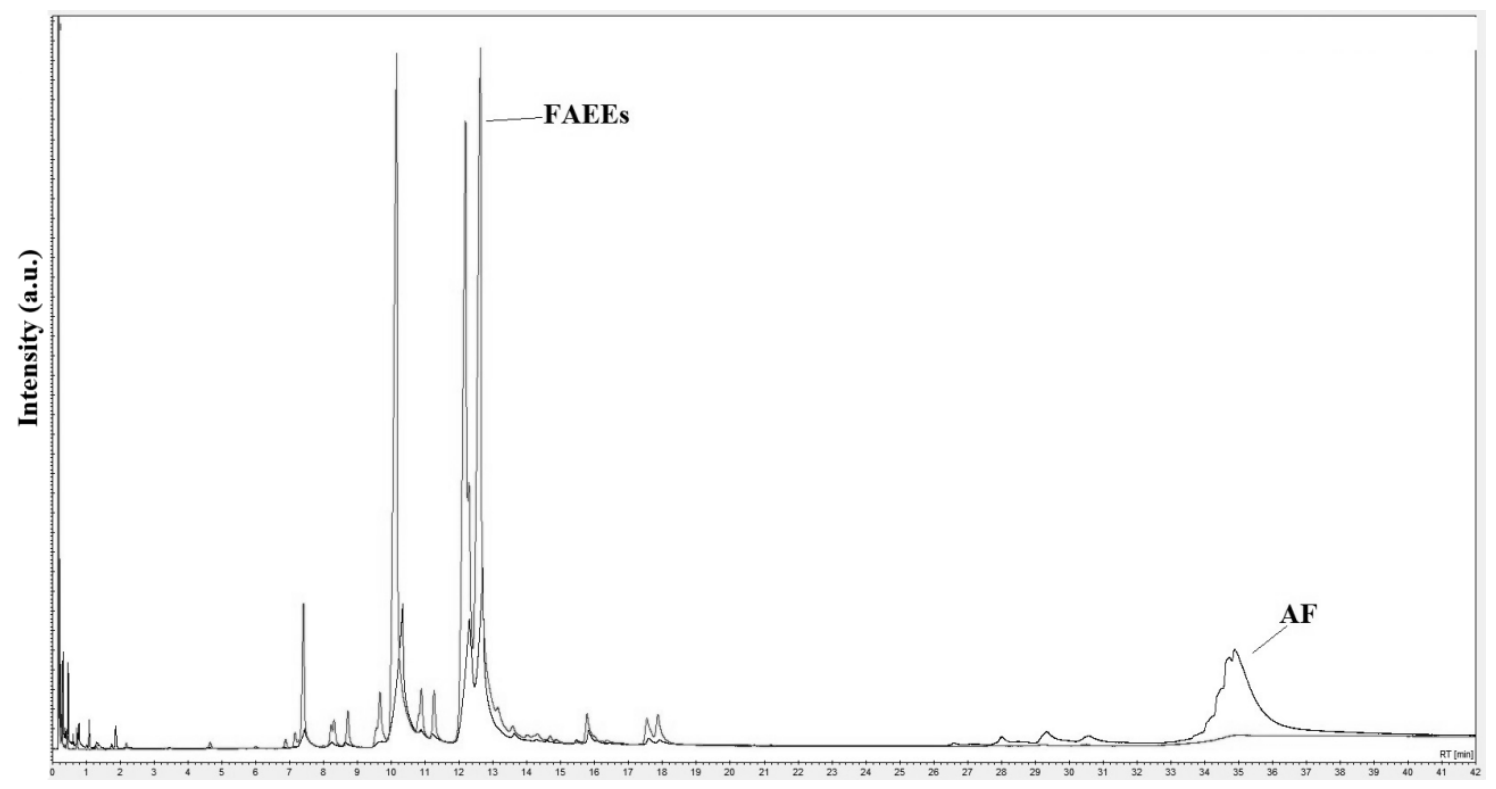

Fig. 3.

Chromatograms representing the FAEEs products obtained from the ethanol transesterification of animal fat $(\mathrm{AF})$ at temperature $240{ }^{\circ} \mathrm{C}$, reaction time $120 \mathrm{~min}$., molar ratio water/fat $=5$ and molar ratio ethanol/fat $=10$. 


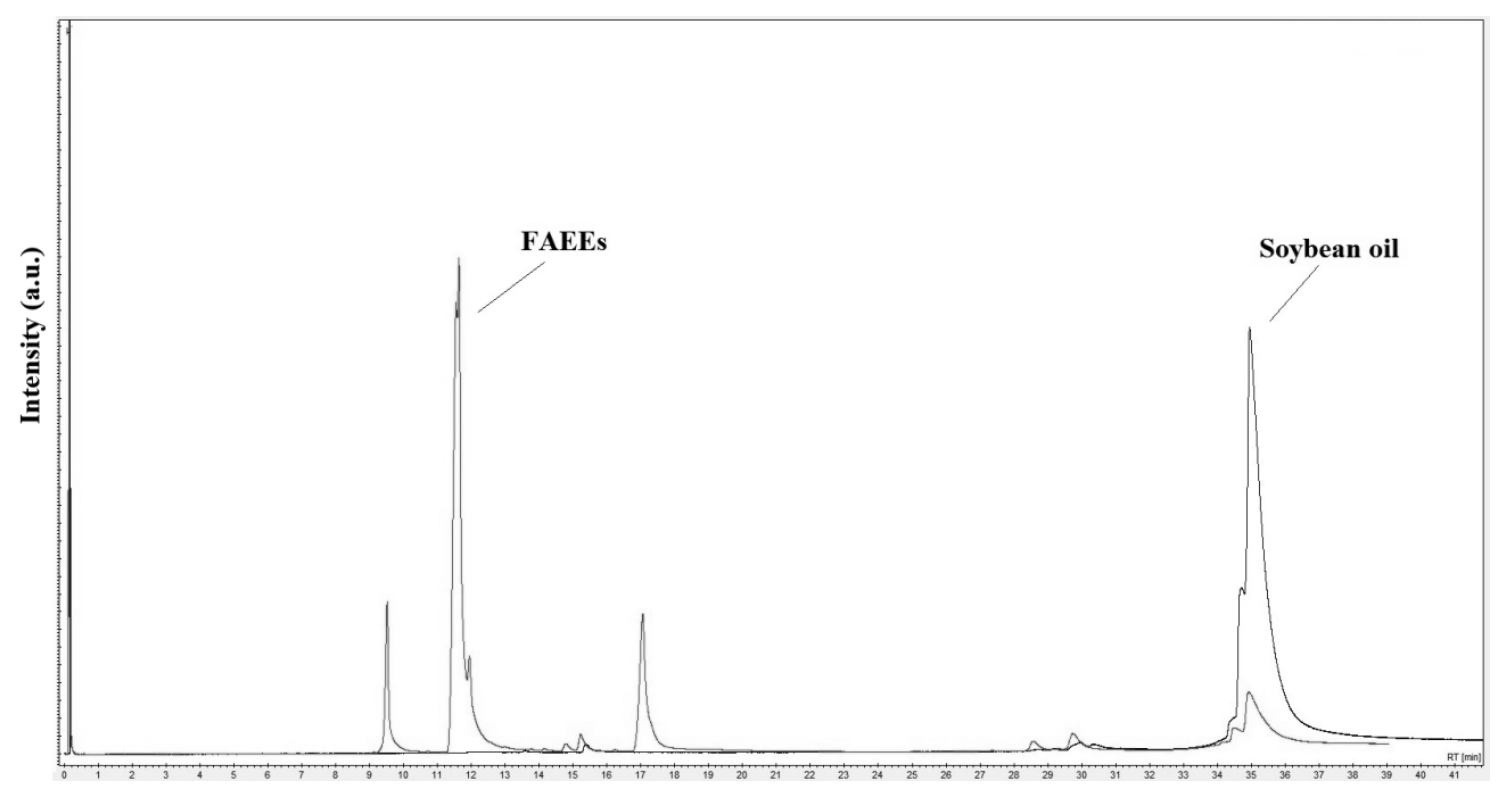

Fig. 4.

Chromatograms showing the FAEEs obtained from the ethanol transesterification using soybean oil at temperature 240 OC, reaction time 120 min., molar ratio water $/ \mathrm{TG}=5$ and molar ratio ethanol/TG $=10$. 


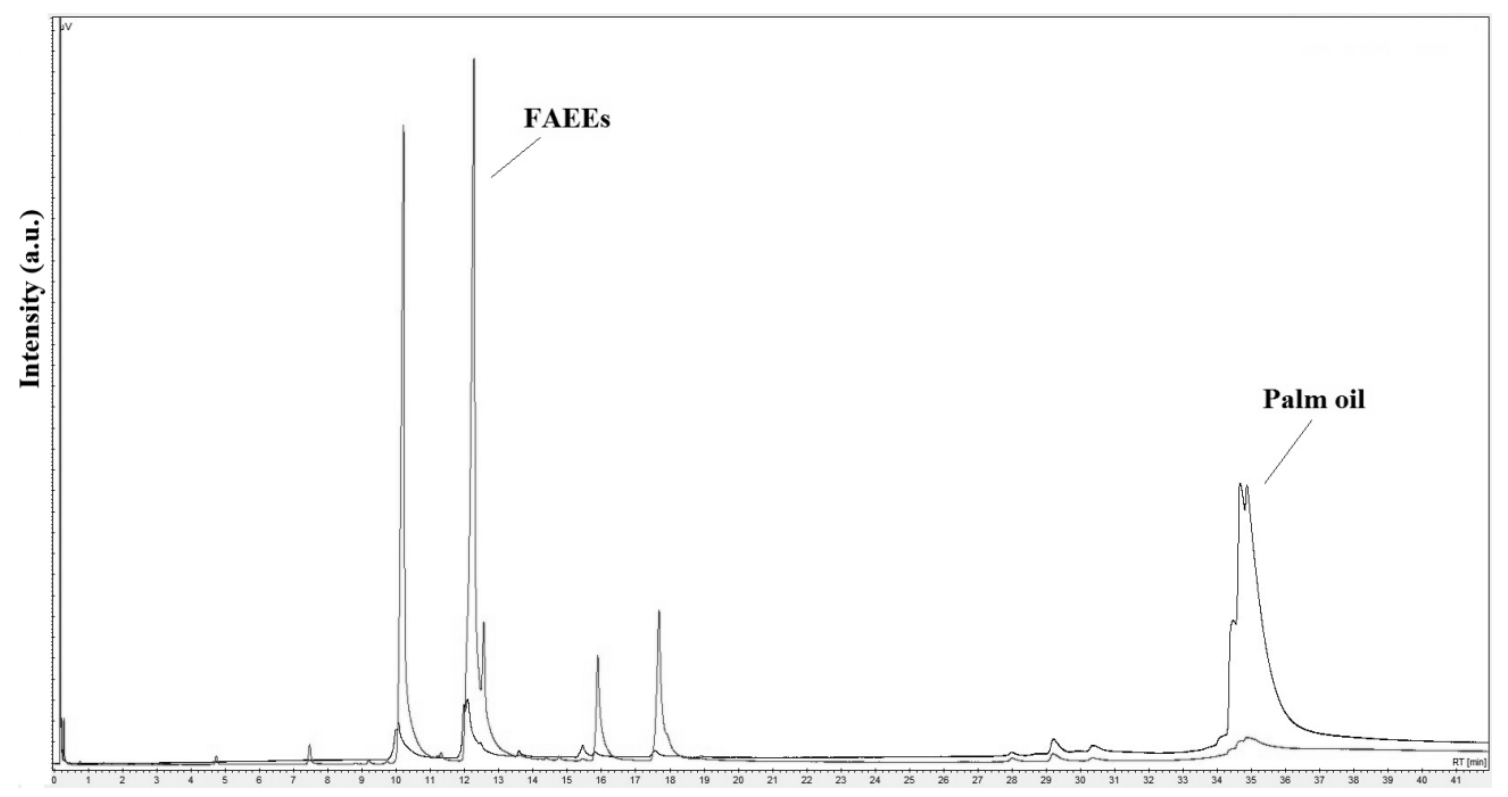

Fig. 5.

Chromatograms showing the FAEEs obtained from the ethanol transesterification of palm oil at temperature 240 OC, reaction time $120 \mathrm{~min}$. , molar ratio water/TG $=5$ and molar ratio ethanol $/ \mathrm{TG}=10$. 